\section{AHA Provides Strategies for Implementing Safer Needle Devices}

The American Hospital Association (AHA) has developed a publication outlining programs to get safer needle devices into the hands of healthcare workers. This 40-page booklet, Implementing Safer $\mathrm{N}$ eedle $\mathrm{D}$ evices, contains an update on federal legislative and regulatory initiatives, a summary of the New York State pilot study of needlestick prevention devices, updated data on occupationally acquired HIV, case studies of hospitals that have successfully implemented safer needle devices, tools for collecting needlestick injury data and evaluating products, and resources on product availability.

To order the booklet, call the American Hospital Association, Order Processing, at 1-800-AHA 2626 (catalog no. 196310).

\section{State TB Control Laws Antiquated}

Many states established TB control statutes at the turn of the century, focusing on power to quarantine, isolate, or commit to a state facility, according to Lawrence Gostin in his survey of all 50 states. However, only half the states specifically grant health officials the power to impose treatment or protect the confidentiality of patients with communicable diseases. Gostin recommends future TB control laws balance public health and human rights with a flexible range of public health powers. Compliance-enhancing strategies are also key, Gostin said, and should include incentives, social support, education, treatment, and housing.

FROM: Gostin LO. Controlling the resurgent tuberculosis epidemic: a 50-state survey of TB statutes and proposals for reform. JAMA 263:255-261;1993.

\section{First Serologically Documented Cases of Hepatitis E Among U.S. Travelers}

Acute hepatitis $\mathrm{E}$ infection has been documented among six persons in the United States who returned from international travel from 1989 through 1992. A recent report from the CDC describes four of these cases in detail.

Outbreaks of hepatitis E (ie, enterically transmitted non-A, non-B hepatitis) have occurred in some parts of the world and have been generally related to fecally contaminated water. Until recently, when research-based serologic antibody tests were developed for hepatitis E virus (anti-HEV), no serologic test was available to identify HEV infection. Diagno- sis depended on a history of exposure and exclusion of other causes of viral hepatitis. However, the sources of infection could not be established. The four persons reported by the CDC represent the first serologically documented cases of HEV among U.S. residents who have returned from travel abroad.

Prophylaxis with immune globulin prepared from plasma collected in the United States is unlikely to prevent HEV infection. When traveling to developing countries, travelers must diligently avoid food and water that is potentially contaminated with human feces.

FROM: CDC. Hepatitis E among U.S. travelers, 19891992. M M WR 42;1993.

\section{Guidelines Available for Managing TB and HIV in the Workplace}

The National Leadership Coalition on AIDS recently issued the first guidelines to be published that deal with both HIV and TB in the workplace. This free publication, M anaging TB and HIV in Today's General Workplace, provides answers to the most commonly asked questions and addresses key issues, such as screening of employees, risks of transmission, return to work policies, and implications of the Americans with Disabilities Act. To order, call 202-429-0930.

\section{New York Begins 24-Hour Hotline for AIDS Clinical Drug Trial Information}

The New York State Health Department started a 24-hour hotline to keep doctors and patients informed about the latest drug treatment for HIV-infected persons. The telephone line also gives information on clinical drug trials and how these drugs are available to those who can't participate in clinical trials. Through an interactive system, updated daily, the callers can give details about specific illness (eg, T-cell counts), and drug information is then matched to these details. The toll-free number is 1-800MEDS4HIV. Out of state, call 212-239-5523.

\section{Glaxo, Inc., Releases Video on Preventing Occupational HIV Infection in Healthcare Workers}

An educational video and 30-page monograph, HIV and the Healthcare Worker, discuss HIV prevention and demonstrate universal precautions, with particular emphasis on managing "sharps." A model postexposure management program is featured, 